\title{
Dialéctica y práctica política en Althusser. Efectos de Maquiavelo
}

Aldo Avellaneda

Centro de Estudios Sociales

UNNE - CONICET

\begin{abstract}
Resumen:
En los últimos cinco años se ha producido un verdadero revival althusseriano fundamentalmente recortado por sus últimos intereses y producciones. Esto ha venido a completar un cuadro en el que se dibuja una especie de anfisbena, un monstruo de dos cabezas y en la que cada una resulta claramente distinguible de la otra. El Althusser estructuralista y dogmático, el que corrige a Marx siguiendo a Marx; y el de la aleatoriedad y el encuentro. Marx, Mao y Bachelard de un lado, Maquiavelo y Epicuro del otro. Frente a esto, el escrito intenta leer uno de los primeros y más reconocidos artículos de Althusser, Contradicción y Sobredeterminación, como un enfrentamiento cuyos actores son inmanencia, política y dialéctica. Para esto y en un primer momento se explicitan las condiciones respecto del problema del sujeto (unidad de la conciencia) para pasar de allí al problema de la estructura (unidad de las prácticas).
\end{abstract}

Introducción:

Es realmente difícil tratar de situar la producción althusseriana, más allá y más acá de lo ideológico y el sujeto, en clave de una discursividad filosófico-política. Esto en parte debido a las regiones en las que el mismo Althusser gustaba de ubicarse y en las que posteriormente fue ubicado con recurrencia. $\mathrm{Y}$ es que lo discutido respecto del pensamiento althusseriano durante los '70 y los '80 fue más que nada una epistemología. Los puntos de interés estaban puestos en la periodización de las obras de Marx, en su distancia de Hegel o lo que en aquellas y en éste había de ideología y de ciencia. Claro que esto tenía influencias en otras zonas de disputa, el problema del humanismo y una visión del sujeto correspondiente. Esta discusión estaba recortada además sobre una producción concerniente fundamentalmente a la del segundo lustro de los '60 así como algunas obras menores de principios de los ' 70 . 
Sin embargo, podría responderse, siguiendo el tenor de las últimas publicaciones - inéditas en algunos casos - esta discusión ha sufrido un fuerte desplazamiento y por fin ha llegado el momento en que el Althusser político habría cobrado vida. El último decenio de su vida académicamente activa estaría marcado por un fuerte distanciamiento de las posturas precedentes (BALIBAR, 2004; DE IPOLA 2007) a la vez que apoyado fuertemente en Maquiavelo, Spinoza, y hasta Epicuro.

Ahora bien, esta diferenciación por regiones o etapas del pensamiento althusseriano debería poder salvar algunos contraargumentos.

El primero. En realidad, la referencia a Maquiavelo en la obra althusseriana es una constante. El primer curso que Althusser da sobre Maquiavelo es en el '62, lo volverá a repetir diez años después y elaborará, tomando como insumo las notas este último, el escrito para una conferencia de 1977 titulada La soledad de Maquiavelo. Aquel curso contenido en el segundo volumen de los Ecrits Philosophiques et Politiques y editado de manera póstuma - se convertirá a su vez en el Maquiavelo y Nosotros que la editorial Akal ha reeditado en castellano hace unos cinco años. Por último, tenemos al Maquiavelo no publicado, ese último capítulo de la última obra que será - también a último momento separado y guardado en una carpeta con la inscripción "La única tradición materialista".

El segundo. Negri, en su ensayo introductorio a Maquiavelo y nosotros, y leyendo los manuscritos del curso del '62 menciona que la conclusión althusseriana es decepcionante ya que se sostiene sobre los caminos trillados que hacían del florentino un "preparador teórico" de la maquinaria de poder necesaria para apoyar los cambios vertiginosos que asomaban en el orden económico - político. Maquiavelo, según la lectura que Althusser le dedica ese año (1962), más allá de romper con la teoría política clásica al pensar materialmente a la política (este es el único punto que le concede Negri), no habría dejado huella alguna en Althusser, no habría producido en éste más de lo que produjo en otros marxistas (Horkheimer e inclusive Gramsci), algunas sorpresas que oficiaban de excepciones a la regla. Habrá que esperar hasta el curso del $71-72$, y especialmente la conferencia del '77 para ver verdaderos efectos de Maquiavelo en Althusser.

Sin embargo, al leer uno de los ensayos más potentes de Pour Marx, "Contradicción y Sobredeterminación", escrito en diciembre del '62, es decir, al final del año del primer 
curso sobre Maquiavelo, es imposible no notar un análisis de superficie, el análisis mismo parece ser una especie de "barrido de superficie". Los elementos en consideración, la relación existente entre ellos, la manera de pensar el cambio e inclusive ciertas imágenes de acontecimiento, aluden a la presencia de una dinámica de las fuerzas, de sus orígenes, sobre las que en la literatura existente no se observa detenimiento ${ }^{1}$.

Esto, presente por otra parte en otros textos de la tradición marxista como El 18 Brumario, La guerra civil en Francia, o ¿Qué hacer?, tiene la particularidad en Althusser de encontrarse junto al intento de conceptualizar estas "eficacias" de las "diferencias", "a partir de lo que son y según las modalidades específicas de su acción" (ALTHUSSER, 2004a: 81). La tarea es emprendida por el lado de una reconceptualización de la dialéctica, de su sentido y de sus estructuras. Su efecto más conocido, la individualización de dos dialécticas, la hegeliana y la marxista, por la vía de la identificación del tipo de contradicción actuante en cada una de ellas, siendo aquella pensada por Marx una contradicción sobredeterminada.

Bien, ¿pero qué significa aquí que una contradicción esté sobredeterminada?, ¿en qué sentido se ajusta al movimiento de autodespliegue de una serie de elementos comunes?, ¿se organizan sin problemas un pensamiento racionalizante, tipificador y jerarquizador como el de la dialéctica con un concepto proveniente del psicoanálisis, destinado a nombrar el carácter contingente de las formaciones oníricas?

Si tenemos en cuenta que lo que estaba en juego era la manera en que se tramitaba el problema de la unidad de una totalidad, del todo social, en definitiva, el de brindar un reaseguro a la unidad de las prácticas, las respuestas a estas preguntas darán la pauta sobre la existencia o no de efectos de Maquiavelo en el Althusser de principios de los '60.

Sin embargo, y teniendo en cuenta que la discusión también se llevaba a cabo frente a posiciones humanistas e historicistas, para llegar al problema de la unidad de las prácticas es necesario detenerse en el movimiento crítico desplegado sobre el de la unidad de la conciencia, es decir, el problema del sujeto.

\footnotetext{
Precisamente, debido en parte a la individualización casi automática de las problemáticas según qué periodo de la producción althusseriana se tome y en la cual el problema estrictamente político se suspende sobre la producción del último periodo.
} 
Una pregunta dirigida al mito

Lo que sigue puede ser leído por entero como una pregunta dirigida al mito del la inexistencia de sujeto en la teoría althusseriana en general y en su teoría de la ideología en particular. Ciertamente, son las prácticas y los rituales los que constituyen al sujeto, también es cierto que el discurso científico es un discurso sin sujeto, esto lo sabemos porque lo manifiesta el mismo Althusser. No es a esto a lo que llamamos mito. Más bien se trata de aquél que se impone, para utilizar una bella frase de Nietzsche, "con la violencia propia de las ideas fijas". En Althusser no hay lugar para el sujeto. De esto claramente se dedujo que Althusser no era precisamente el mejor partido para pensar la práctica política. Que el texto Ideología y aparatos ideológicos del Estado pueda ser pensado en torno a la práctica política y al rol de los sujetos en ellas es algo que - contra toda evidencia - se presenta con una obstinada coherencia si pensamos en el problema que inicialmente se plantea, el de indagar la manera en que un modo de producción perdura en el tiempo. A su vez, interesa a Althusser no el problema de la reproducción de los medios de producción sino la reproducción de la fuerza de trabajo así como de las relaciones de producción. Y aquí encontramos lo central del punto: los aparatos ideológicos son los encargados de generar constantemente un marco de coherencia sobre unas prácticas tales que sean lícitas al sistema dominante. Al mismo tiempo que aprendemos lo bueno que son la matemática y la historia, vamos lentamente internalizando todo el sistema de "saberes prácticos", nos enfrentamos a la "evidencia" de sus beneficios.

El seguro y la cobertura social en el trabajo por otra parte, sin contar con la estabilidad normativo-institucional y fundamentalmente socioeconómica, son una prueba irrefutable del éxito del mecanismo. La ideología son estas prácticas, no se trata solamente de representaciones ni de espíritus de época.

Sucede que tal vez una de las primeras dificultades de este texto se ubica en que el problema sobre el que se centra es excedido ampliamente por las tesis que enuncia, con lo cual pareciera ser que el problema se queda a mitad de camino. La ideología en Althusser se presenta, como es sabido, a la hora de pensar en las condiciones de reproducción de las relaciones de producción. Ahora bien, en el camino de la argumentación se afirman 
cuestiones tales como que la ideología es eterna, que interpela a los individuos como sujetos, que existe por y para sujetos, etc. Todo esto en forma independiente a las relaciones de producción de un modo de producción determinado. Tenemos aquí un mecanismo invariante e independiente - al menos en su forma - de la cuestión de los modos de producción.

Pero Althusser debe recurrir a saltos constantes entre la Ideología y las ideologías debido precisamente al problema que se había planteado y que, siguiendo las tesis enunciadas, suponía pensar la manera en que este mecanismo invariante se relacionaba con otro, "mecanismo" también, aunque sujeto a variaciones históricas, precisamente la cuestión del modo de producción. Allí es dónde aparece el Estado como eje articulador entre ambos.

La primera definición que nos da el texto de Estado es la los clásicos del marxismo, de "Estado represivo" y “'máquina' de represión que asegura que la clase dominante asegure su dominación" (ALTHUSSER, 2008: 110). Más allá de que le "falte algo" a esta definición, Althusser no se despegará un ápice de ella y dirá que contiene lo esencial ${ }^{2}$. El punto es que, del hecho de que toda la lucha de clases gire alrededor de la posesión del aparato de Estado, los aparatos ideológicos son pensados a priori como partes del poder del Estado. Así, no solamente el sistema escolar, sino la familia o las distintas iglesias son pensadas como aparatos del Estado. ¿Dónde encontramos los fundamentos que justifiquen esta unidad? En el afán por no caer presa de la "ideología jurídica burguesa" y su distinción entre lo público y lo privado. Ciertamente, "las instituciones privadas pueden perfectamente funcionar como aparatos ideológicos del Estado" (ALTHUSSER, 2008:117) Bien, pero la pregunta subsiste, ¿qué sería "funcionar como aparatos ideológicos de Estado”?, más allá de la circularidad del argumento ${ }^{3}$, lo importante - que recién una década después quedará

2 Mientras que en 1969 Althusser parece englobar bajo el concepto de aparato de Estado a los aparatos represivos y político-burocráticos - si bien lo designa repetidamente como aparato represivo, al menos en tres ocasiones se puede observar la inclusión explícita de lo jurídico-burocrático, (ALTHUSSER, 2008: 110, 115 y 118) - diferenciándolo de "otra realidad"(los AIE), en 1978 realiza clara distinciones entre cada uno de ellos.

3 Mientras que por un lado expone que "... la unidad entre los distintos aparatos ideológicos se asegura... por la acción de la ideología dominante (la de la clase dominante)...” (ALTHUSSER, 2008: 121) y lo refuerza diciendo, con un status de tesis que "no hay práctica sino en y por una ideología" (ALTHUSSER, 2008: 138) por el otro repite machaconamente el carácter material de la ideología, carácter que no es otro que el de las prácticas. 
explicitado - es el fin en el que colaboran. Basta con que contribuyan a la reproducción del modo de producción. Sí, basta con considerar este hecho para determinar su punto de adscripción y del cual son copia y calco. Claramente, el Estado adquiere un rol centralizante sumamente excesivo a la vez que con el concepto de "ideología dominante" Althusser parece subsumir complejas diferencias sin dar cuenta de ellas ${ }^{4}$.

Es que la reproducción de unas determinadas formas de vida se da en múltiples espacios y tiempos, y es esto lo que se relaciona en Althusser con la temática del sujeto, ya que, simplificación brutal mediante, podríamos afirmar que toda sociedad se reproduce produciendo sus sujetos. Y esto no podría lograrse sin instituciones ni prácticas porque entre los individuos y sus condiciones reales de existencia hay una relación que se da en el orden de lo imaginario. Reconocemos esta relación por medio de la Ideología, más precisamente por una de sus dos funciones, la del reconocimiento ideológico.

La función de este reconocimiento nos garantiza nuestra relación con el mundo, nos hace saber que "somos seres concretos, individuales, inconfundibles, y (naturalmente) irremplazables" (ALTHUSSER, 2008: 140), nos permite presuponer con total tranquilidad que "yo" soy el que fui hace veinte años y el que esta mañana, al despertar, saludé a mi pareja en la cama. La unidad en la representación del sujeto sobre sí es una necesidad del individuo que no responde únicamente ni puede justificarse por el desarrollo de una misma corporeidad.

Y aquí está otra de las consecuencias del exceso de las tesis respecto del problema planteado. En consonancia con este último, toda práctica es entendida como "normada por rituales" y "al interior de los aparatos ideológicos". Sin embargo, resulta difícil entender cómo el saludo que dirigimos a nuestros amigos en la calle - cotidianeidad que le sirve a Althusser para demostrar la ubicuidad del mecanismo ideológico - es un ejemplo de una práctica tal. En el mismo Althusser encontramos un ejemplo que sin embargo niega la ecuación efecto ideológico = dominación. En torno a El Príncipe, Althusser manifiesta, "Es sorprendente, porque tanto como un texto puede hacerlo, nos cuestiona y nos sitúa

4 Basta ver los "temas" que integran la "partitura dominante" (ALTHUSSER, 2008: 125) para tener una idea de la inflación del concepto. 
políticamente. Nos interpela a partir de un lugar que nos llama a ocupar como 'sujetos' (agentes) posibles de una práctica política posible" (ALTHUSSER, 2004b: 67).

Distanciándonos del efecto teórico centralizador de la categoría de Estado se pueden proponer otros ejemplos no menos evidentes. En el caso del enunciado publicitario "Tomá Coca-Cola". A esta empresa le importa poco que alguien en particular consuma el narcotizante producto. Le interesa que todos lo hagan o, al menos, cuantas más personas lo hagan mejor. El sentirme interpelado, el creer que me habla a mí (actualizando al mismo tiempo mi condición de ser yo, el mismo y el único), es el suplemento que constituye la esencia del mecanismo de interpelación ideológica. Con esto queremos nada más indicar que dicho mecanismo, que Althusser define para pensar el funcionamiento de los aparatos ideológicos del Estado y a éste en su papel en la reproducción de las relaciones de producción, excede el dominio en el que estos actúan. Sea porque la interpelación se produce desde otros centros de poder, sea porque no hay relación de poder explícita en la interpelación.

Precisamente, si lo ideológico funciona reclutando sujetos para su causa y si vemos que el mismo Althusser da ejemplos del funcionamiento de lo ideológico en regiones no controladas por los aparatos, ¿podemos seguir admitiendo que la sola mención al carácter eterno de la Ideología nos habilita a pensar en un sometimiento por igual término al modo capitalista de producción y a sus formas de vida? La Ideología, no el Estado, es omnipresente. Los aparatos de Estado no ahogan el espacio y el tiempo. Hay prácticas que no controlan. No hay sujeto autoconsciente pero tampoco objetivación de la historia.

Negri, en cierto sentido, trabaja con el mismo presupuesto cuando afirma que el comunismo ya no se nos da como horizonte y proyecto, sino más bien como resistencia, "ahí donde los cuerpos se organizan, en intersticios del poder capitalista en los cuales viven (...) relaciones de comunidad, ahí en donde las resistencias producen zonas en donde no reinan las 'relaciones del mercado"” (ALTHUSSER, 2004b: 17). Existen mojones, conjunto de prácticas - interpelaciones en las que se configuran determinadas subjetividades.

Este punto es también advertido por Eagleton (EAGLETON, 2005: 191). Las interpelaciones de la ideología dominante no son todas exitosas. Podemos no reconocer el 
llamado de una ideología en particular (aunque necesariamente debamos hacerlo en alguna, pues lo contrario sería salirnos del orden simbólico), podemos no representarnos nuestra relación con nuestras condiciones de existencia de acuerdo a las condiciones vigentes.

Sucede que Althusser, preocupado por desarrollar un modelo de explicación de la reproducción del sistema se aboca a un tipo de prácticas específicas, las que, según dijimos, están moldeadas por rituales a su vez inmersos en los aparatos ideológicos, entendidos todos estos por si fuera poco como del Estado.

Sin embargo, a condición de entender como discontinuo el lazo que une a algunos de los aparatos ideológicos con el Estado y de resaltar la importancia de separar la Ideología como mecanismo de las ideologías producto de diferentes esferas de la praxis social, tenemos que la práctica política no solamente es posible, sino que es imposible negarla. Las ideologías (conjunto relativamente confuso de representaciones de relaciones), a diferencia de la Ideología (mecanismo psicoanalítico vital), son históricas, orientadas a la acción de todas maneras posible debido a la dominancia sin determinación última, una dominación sin invariancias (BALIBAR, 2004).

Pero aquí ya no estamos en el terreno del sujeto de la Ideología, sujeto por definición indiferenciado, sino más bien en el dominio del sujeto de la sobredeterminación, es decir, de un sujeto atravesado por múltiples procesos de constitución, propios de diferentes dominios de prácticas. Lo central en esto es que el sujeto ya no es el origen de esa conciencia unificada y unificante de las experiencias diversas y discontinuas sobre las que desarrolla su existencia, más allá de que deba dotar de un marco de coherencia al conjunto de sus prácticas. Si la unidad de las prácticas no las da el sujeto hay que ir a buscarlas a otro lugar.

Así, todo el problema de la unidad de las prácticas se traslada a la manera en cómo se entienda el "todo social", pues es en su compleja articulación en el que las prácticas tendrán un sentido. Esta cuestión fue planteada explícitamente en el texto del '69 pero con mayor detenimiento en La revolución teórica de Marx, principalmente en "Contradicción y Sobredeterminación” y "La dialéctica materialista”. Retrocedamos pues.

- ¿Unidad de las prácticas? 
Para Althusser hablar de la totalidad social desde un enfoque estrictamente marxista no puede sino implicar un "todo estructurado complejo". Se trata de la tesis epistemológica fundante del "todo ya dado" en palabras de Badiou (BADIOU, 2008), es decir, del hecho de que en todo momento nos topamos con relaciones y sistemas de relaciones, no damos jamás con el elemento último y originario del cual podríamos comenzar a deducir todo lo demás.

Si bien toda idea de contradicción indica, antes que elementos, una relación, indica además una modalidad específica de esta relación, pues el campo en el que esta se encuentre siempre por definición deberá soportar las condiciones para una dicotomización. Una relación contradictoria, sea en la lógica parmenídea o en el materialismo dialéctico, es de tipo A - no $\mathrm{A}^{5}$.

Una reformulación de esto supuso una enmarañada discusión acerca del carácter específico de la dialéctica marxista y de la contradicción que contenía. Parece ser necesario un rodeo por ella para dar cuenta del sentido del concepto sobredeterminación y el lugar que por su intermedio parece quedar habilitado para pensar la práctica política y su sujeto. Yendo directamente al pasaje que origina la discusión, Marx había escrito:

\begin{abstract}
"Mi método dialéctico no solo difiere del de Hegel, en cuanto a sus fundamentos, sino que es su antitesis directa. Para Hegel, el proceso del pensar, al que convierte incluso, bajo el nombre de idea, en un sujeto autónomo, es el demiurgo de lo real; lo real no es más que su manifestación externa. Para mí, a la inversa, lo ideal no es sino lo material traspuesto y traducido en la mente humana. [...] En él, la dialéctica está puesta al revés, es necesario darla vuelta, para descubrir así el núcleo racional que se encuentra en la envoltura mística" (MARX, 2002: 19 -
\end{abstract} 20)

Althusser parte de asimilar - movimiento por lo demás formal - el "núcleo racional" a la dialéctica y la "envoltura mística" a la filosofía especulativa hegeliana. Pero luego da un

5 Dejamos de lado la importantísima cuestión de hasta qué punto podemos pensar relaciones entre objetos de la misma manera que pensamos relaciones entre juicios. 
paso inesperado al preguntarse cómo, de qué manera, este "núcleo racional" puede ser descubierto de su "envoltura" a través de una inversión (admitiendo, claro está, con Marx, que "descubrimiento" e "inversión" son partes de un mismo momento).

Si para Hegel lo real no es más que la manifestación externa de la idea y no más que eso, ahora la vemos como un simple epifenómeno reflejo de lo real (y no más que eso). Sin llegar a tocar la dialéctica, la inversión termina siendo de esta manera una inversión del sentido "término a término", todo lo cual nos terminaría dejando - de acuerdo a Althusser en Feuerbach y no en Marx. Y el problema para Althusser es que, concebida la dialéctica de esta manera, lo esencial del pensamiento hegeliano es retenido y con ello, todo es reencauzado a un centro y a su autodespliegue binario.

En la idea de inversión que la tradición marxista ha sostenido, la "envoltura mística" no mantiene un tipo de relación externa al método (el "núcleo racional", la dialéctica) sino que es a su respecto, constitutivo. Es ella quien otorga un sentido claramente definido a la dialéctica y a los principios que la sustentan, de allí la intuición de Althusser de que la "extracción” por "inversión" mantiene aún intacta su forma mistificada. Se trata más bien, para Althusser, y siguiendo en este punto a Rancière (ALTHUSSER, 2004c) de la inversión expresión metafórica.

Pero el problema de la expresión metafórica para Althusser es que no expone la naturaleza distintiva del objeto al cual se refiere (la idea en Hegel, el mundo real en Marx) y en relación con el cual el método configura sus características. Es más, las sucesivas interpretaciones (véase aquí una tabula rasa que recorre los extremos pensables de Engels a Lukàcs) tendieron a utilizar el método asimilando, si bien de manera invertida, la estructura de la dialéctica hegeliana en su totalidad. Para Althusser, en cambio, si la dialéctica marxista es en principio opuesta a la hegeliana, se trata no solamente de una inversión de "sentido", sino de una radical distinción que debe manifestarse en sus estructuras y determinaciones.

En contraposición a aquella que se encuentra en Hegel, llamada por Althusser "contradicción simple" (y que tiene por objeto, lo repetimos, la idea), en la que cada elemento espera su turno para ser "superado" en una próxima síntesis, la especificidad de la dialéctica marxista radica en que incluye (por el carácter del objeto del que trata) una 
contradicción sobredeterminada, una contradicción que puede o no tener carácter de "antagónica", que tiene un aspecto principal y un aspecto secundario, de acuerdo a la estructura del cuerpo social en la que se encuentre. Es por esa misma razón, por tener por objeto el sistema de relaciones ya dadas, que una contradicción, al ser inseparable de sus condiciones formales de existencia, es afectada por ellas, determinando aunque también siendo determinada en un único y mismo movimiento por las diferentes instancias y niveles de la formación social en la que se encuentra.

Con respecto a Hegel Althusser dirá que la simplicidad de la contradicción expuesta en el tipo de dialéctica por él edificada solo es posible gracias al principio interno que constituye - para Hegel - la esencia de cualquier periodo histórico, principio que permite reducir la totalidad, ("la infinita diversidad" dice Althusser) de elementos que hacen al "mundo real" (prácticas políticas, jurídicas, económicas, etc.) en cualquier época histórica (desde la Grecia Clásica a nuestros días), a una contradicción simple, de tipo biunívoca. En cambio, la contradicción Capital - Trabajo nunca es simple, todo lo contrario, siempre estará determinada por las formas históricamente concretas en las cuales sea ejercida.

Ya no es posible fijar el elemento contradictorio de antemano sin estudiar la coyuntura específica, sus prácticas políticas o ideológicas. Estas últimas, unidas a las económicas, pueden sobredeterminar - efecto de condensación de un cúmulo de contradicciones sobre un punto - un espacio social en un momento determinado. La ambivalencia althusseriana en este punto es radical ya que si por un lado el concepto de sobredeterminación le otorga un renovado estatus a una serie de elementos (pues la operación consiste en introducir nuevos puntos de apoyo en la serie de relaciones de fuerza propias del capitalismo), por otro lado seguirá sosteniendo la fórmula de la determinación "en última instancia" de la economía, con lo cual, para muchos de sus críticos, el segundo de los términos limita claramente la existencia del primero. La lucha parecerá inclinarse sin embargo - aunque sin ser definitivamente resuelta - tras un movimiento de tipo retórico - teórico, "Ni en el primer instante ni en el último, suena jamás la hora solitaria de la última instancia" (ALTHUSSER, 2004a: 93).

La simplicidad del principio interno que en Hegel se encarga de reducir lo real es esa relación par, relación entre dos elementos que, como se sabe, en realidad es uno 
conteniendo al otro como tal. La distancia de este principio respecto de una relación que es inseparable de sus condiciones de existencia es una distancia de planos. El principio interno hegeliano trabaja sobre el plano del Logos y de su representación del mundo. Aquí tenemos al Espíritu que es Uno y que deviene, que se realiza en la historia. Por otro lado, el plano de la superficie de los hechos, determinado relacionalmente, estructurado, y en ciertas ocasiones dicotomizado debido a "unidades de ruptura". Pero estas unidades de ruptura no serán sino "fusiones" o "condensaciones" de algunos elementos de esa superficie. Althusser recoge así el gesto de inmanencia contenido en Maquiavelo, incorporándolo de una manera oblicua por vía del concepto de sobredeterminación y provocando finalmente con éste una empresa sumamente inestable (e inesperada por cierto): reorganizar los elementos de la dialéctica en función de una lectura inmanente a las prácticas políticas.

\section{Conclusión}

Althusser provoca el despegue del concepto de contradicción del lastre que históricamente tuvo por ser arrancado del dominio de la lógica, el lastre de una concepción esencialmente dicotómica (estrictamente hablando, dicotomizante) de lo real pues la matriz de las posibilidades orientada por el hecho de que el gato esté y no esté en el sofá a la vez, matriz que había donado el sentido a una realidad que terminaba encorsetando, ya no delimita el rango de las relaciones de fuerza pensadas y pensables (puesto que se trata también de una nueva modalidad del pensar).

El concepto de sobredeterminación permite la apertura hacia otro sistema de causalidades. Un sistema causal plural (no solamente superior a Uno, sino a dos). Esto es lo problemático para la dialéctica, puesto que en su interior Althusser ya ha comenzado a teorizar la diferencia en el peso específico de los elementos.

\footnotetext{
"Las diferencias que constituyen cada una de las instancias en juego (...) al fundirse en una unidad real, no se 'disipan' como un puro fenómeno en el interior de una contradicción simple. La unidad que constituyen con esta fusión de ruptura revolucionaria, la constituyen con su esencia y eficacia propias, a partir de lo que son y según las modalidades específicas de su acción” (ALTHUSSER, 2004a: 81).
} 
En este terreno Althusser está pensando en estrategias, la de Lenin y del eslabón más débil, que "inspira también su reflexión en la Revolución misma" (ALTHUSSER, 2004a: 76), con lo cual queda claro que la revolución es un asunto de estrategia política - , y apoyado en otro grande del género, el Marqués de Vauban. Para Althusser "Rusia era el eslabón más débil de la cadena de Estados imperialistas... porque acumulaba la mayor cantidad de contradicciones históricas entonces posible" (ALTHUSSER, 2004a: 78). Se trata entonces de un conjunto de relaciones no subsumidas unas en otras hasta lograr la relación esencial, es decir, la contradicción principal. Y si se habla de tal contradicción de todas maneras Althusser está lejos de retener el aspecto central de aquella que había servido como modelo, relaciones de producción / fuerzas productivas. Estas relaciones están generadas por condiciones relativamente independientes, provenientes de regiones diferentes.

Pensando en la complejidad de la práctica política Althusser parece haber dejado abierto un pensamiento acerca del movimiento en aquella dialéctica que se había decidido a estudiar, “... la 'superación' en Marx, mientras esta palabra tenga todavía un sentido, (a decir verdad no tiene ningún sentido riguroso), no tiene nada que ver con la dialéctica de la comodidad histórica" (ALTHUSSER, 2004a: 95). Ya no es posible negar el efecto de la sobredeterminación en el aparato conceptual marxista y particularmente en su concepción de la historia y del devenir. Si bien Althusser establece un "índice de eficacia", por ende, un juego de jerarquías entre las contradicciones, ya no tenemos una anticipación de sentido, la filosofía se evade de la dimensión logocéntrica que la identifica "con una función del logos encargada de pensar la anterioridad de sentido sobre toda realidad" (ALTHUSSER, 2003: 33) tenemos una tendencia.

La unidad de las prácticas, más allá de la repetición casi hipnótica del término estructura o dialéctica, es una unidad articulada por relaciones que están en un "todo ya dado" y del cual no es posible asegurar a futuro la disposición efectiva de las fuerzas.

Del mismo modo en que la Ideología excede las regiones de operatividad de los aparatos, aquí las relaciones sociales cobran, al momento de configurarse como tales, un sentido que recién allí puede estar definido en relación a las estructuras elementales de poder. El aporte específico de la categoría de sobredeterminación a este punto es que permite pensar la 
concurrencia de contradicciones generadas por causas diferentes, existiendo o no relaciones entre ellas o teniendo orígenes comunes.

En definitiva, las grietas para el ejercicio de prácticas políticas que no supongan la reproducción del modo de producción (para seguir utilizando los términos althusserianos) si es que se las pueden pensar como tales, están abiertas desde el mismo entramado conceptual. El problema es que en ellas la dimensión habilitante para una lectura de una subjetividad contrafáctica no halla aún lugar. Este será un problema que acompañará a Althusser hasta mediados de la década de los '80.

Sobre la posición de finales de los '60 es posible pensar, a contrario de lo que supuso Negri, en efectos de Maquiavelo. Tales efectos, aunque producen una serie de innovaciones en relación al pensamiento marxista sobre lo político y el poder (podría considerarse válido el interrogante sobre la denominación de dialéctica de la resultante de la teorización althusseriana), están desacoplados aún de un pensamiento tematizante de la relación subjetividad - poder dado que la fuerza de lo subjetivo ancla en unas prácticas posibles llevadas adelante sin embargo por sujetos imposibles. De allí que la lectura clásica sobre este punto en Althusser no esté dispuesta a asentir - con razón - efectos de Maquiavelo ni innovaciones.

Lo que sí se nos adelanta en el escrito del ' 62 es ese acento de lo político en lo teórico que nos permite en definitiva pasar de una discusión epistemológica a una teoría política, la presencia en definitiva de una noción ambigua y solapada de fortuna. Aquí empieza el brutal reconocimiento de la verità effetualle della cosa. Claro que había aun muy poco lugar para pensar en algo similar a la virtù desde que la concepción del reclutamiento de sujetos devino central para pensar la reproducción del sistema.

Una década más tarde Althusser recurrirá a Maquiavelo de manera explícita y en dos direcciones. En primer lugar para pensar en una práctica política desde el vacío de sus condiciones de posibilidad, tal como se presentaban las experiencias de revolución con base en el imaginario marxista a principios de los '70 en Europa. "Maquiavelo - nos dice Althusser - es el teórico de la novedad, porque es el teórico de los comienzos, del comienzo" (ALTHUSSER, 2004b: 34). 
Pero también con Maquiavelo vendría a reposicionarse en el proyecto político althusseriano una dimensión específicamente relativa al sujeto, fuertemente desplazada en el discurso estructuralista. Lo central de la virtù política es el reconocimiento de la inexistencia de un dominio universalmente válido de aplicación de una conducta. La verità effetualle della cosa intenta proveer del terreno movedizo en el cual una virtù puede ser desplegada. Ella se constituye en el criterio de su aprobación. Aquí el obrar no se desarrolla en un medio que necesita de la vida buena ya constituida para justificarse, como sería el caso del imperativo categórico, cuyo problema, y como lo habían entrevisto Horkheimer y Adorno, es que uno no es toda la humanidad y no puede hablar por ella. El terreno de la coherencia a prueba de flexibilidad es el terreno de una verdad que no puede ser dicha desde posición de poder alguna. No puede ser dicha desde una posición dominante, pero trae no pocos problemas a las posiciones de resistencia.

Althusser, lo mismo que Maquiavelo (en el caso de que, junto con Althusser, lo consideremos filósofo), nunca intentó emplear la filosofía para satisfacer dilemas morales otorgando modelos de acción universalizantes. Más bien trató de desarrollar una praxis soportada no en un bien pleno y universal sino efectivo y selectivo. Los mojones de comunismo real son preferidos en esta época a la generalidad del comunismo como proyecto.

Son dos las coordenadas esenciales para entender los últimos movimientos públicos de un filósofo que vivirá los últimos diez años de su vida escuchando hablar de él: pensar en un nuevo comienzo y reintroducir al sujeto en un proyecto político.

Huelga decir que lo que se ha intentado desplegar aquí son las líneas del enfrentamiento - a principios de los ' 60 - entre los primeros esbozos de este proyecto y la dialéctica, siendo la resultante una prescripción mutua... aunque temporaria.

Bibliografía

- ALTHUSSER, L., (2002) Para un materialismo aleatorio, Arena Libros, Madrid. (2003) Marx dentro de sus límites, Akal, Madrid. (2004a) La Revolución teórica de Marx, Siglo XXI, Bs. As. 
(2004b) Maquiavelo y Nosotros, Akal, Madrid.

(2004c) Para leer El Capital, Siglo XXI, Bs. As.

(2008) La soledad de Maquiavelo, Akal, Madrid.

(2008) "Ideología y aparatos ideológicos del Estado" en La filosofía como arma de la revolución, Siglo XXI, México.

- BADIOU, A., (2008), Teoría del sujeto, Prometeo, Bs. As.

- BALIBAR, E., (2004) Escritos por Althusser, Nueva Visión, Bs. As.

- DE IPOLA, E., (2007) Althusser, el infinito adiós, Siglo XXI, Bs. As.

- EAGLETON, T., (2005) Ideología. Una introducción, Paidós, Barcelona.

- MAQUiAVElo, N., (2007), El Príncipe, Alianza Editorial, Bs. As.

- MARX, K., (1973) El dieciocho Brumario de Luis Bonaparte, Editorial Ateneo, Bs. As. (2006) El Capital, Tomo I, Vol. I, Libro Primero, Siglo XXI, Bs. As. 